\title{
Primary malignant fibrous histiocytoma of the renal pelvis: a 78-month follow-up case report
}

This article was published in the following Dove Press journal:

OncoTargets and Therapy

16 December 2013

Number of times this article has been viewed

\section{YueBing Chen' \\ Dapang Rao ${ }^{2}$ \\ Haibo Zhu ${ }^{2}$ \\ Haifeng $Y^{2}$ \\ ShiKun Yang ${ }^{2}$}

'Department of Urology, Affiliated Sir Run Run Shaw Hospital of Zhejiang University, Hangzhou, ${ }^{2}$ Department of Urology, 2nd Affiliated Hospital of Wenzhou Medical College, Wenzhou, Zhejiang, People's Republic of China
Correspondence: ShiKun Yang Department of Urology of the 2nd Affiliated Hospital of Wenzhou Medical College, Wenzhou Zhejiang, People's Republic of China 325000 Email youngsk@I26.com

\begin{abstract}
Primary malignant fibrous histiocytoma of the renal pelvis is extremely rare. This article reports a pathologically confirmed case. Surgery is the main treatment for this disease. Chemotherapy and radiotherapy have been reported to be ineffective. It is difficult to differentiate it from urothelial tumor of the renal pelvis and renal cell carcinoma by preoperative laboratory and radiological evaluation. Immunohistochemical study is helpful in confirming the diagnosis of the disease. This report discusses the clinical manifestations, pathohistological characteristics, treatment, and prognosis of the case reported.
\end{abstract}

Keywords: primary malignant fibrous histiocytoma, tumor, urothelium, and renal cell carcinoma

\section{Introduction}

Malignant fibrous histiocytoma (MFH), or fibrous sarcoma, is a common soft-tissue sarcoma in elderly populations, and most likely to occur in the four extremities, body trunk, or retroperitoneum. ${ }^{1-11}$ Primary renal MFH is quite rare, and primary MFH of the renal pelvis even rarer. ${ }^{11-15}$ With progress made in clinical studies, advances in pathohistological and immunohistochemical techniques and a further understanding of the disease, correct diagnosis and proper treatment will be possible. In this article, we report the case of a patient with primary MFH of the renal pelvis who has survived a 78-month tumor-bearing follow-up.

\section{Case report}

A 71-year-old woman was admitted because of recurrent macroscopic hematuria of more than 1 year and the magnetic resonance imaging (MRI) finding of a spaceoccupying lesion in the right renal pelvis that had been there for more than 1 month. A year earlier, she had undergone a B-type ultrasound, a computed tomography scan (CT), and MRI of the urinary system because of macroscopic hematuria, but no significant abnormality had been found. After discontinuation of anticoagulants for coronary heart disease, the hematuria subsided. In 2011, macroscopic hematuria was recurrent and self-limited. One month prior to presenting, macroscopic hematuria appeared again, when MRI suggested a space-occupying lesion in the right renal pelvis (Figure 1A).

Physical examination indicated no weight loss, stable vital signs, no palpable mass in the abdomen, and no percussive pain over the kidneys bilaterally. A B-type ultrasound suggested left hydronephrosis and space occupation. On December 20, 2006, 


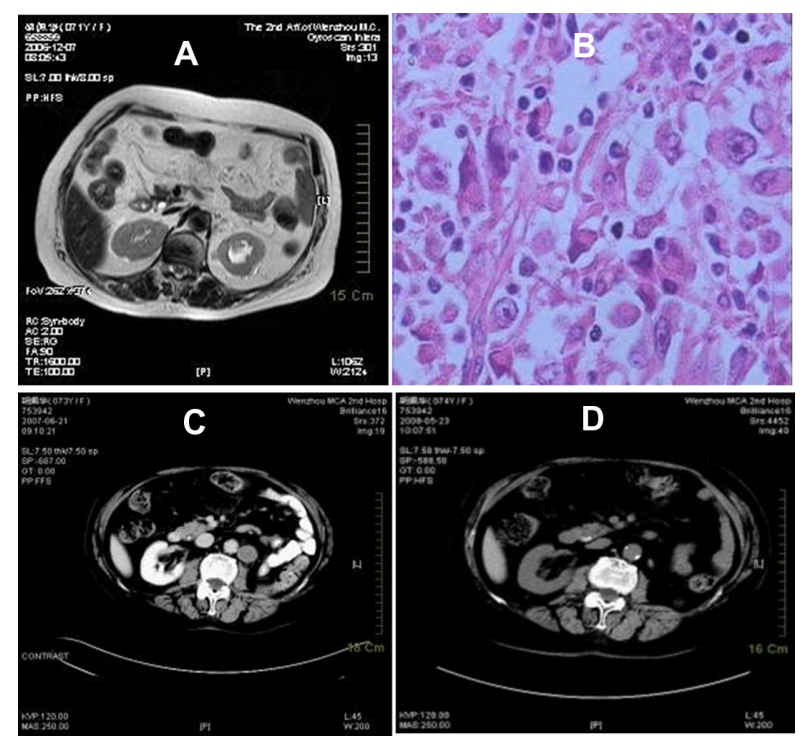

Figure I (A) Preoperative magnetic resonance image; (B) pathologic section; (C) computed tomography (CT) re-examination at 9 months suggesting metastasis near the abdominal aorta; (D) CT re-examination at 18 months showing no enlarged lymph node near the abdominal aorta.

radical nephrectomy, renal vein cancer embolus resection, and peripheral lymph node clearance were performed under general anesthesia. Intraoperative findings were: no infiltration of the left renal capsule and fat cyst; no enlarged lymph node observed near the kidney; a $30 \times 25 \mathrm{~mm}$ white gray tumor in the left renal pelvis; and a bean-sized cancer embolus in the vein of the left kidney. Postoperative pathology reported MFH of the left kidney associated with renal-vein cancer embolus (Figure 1B). Immunohistochemistry showed vimentin (+) and cluster of differentiation (CD) $68(+)$ (Figure 2). (All antibodies were purchased from Maixin Biotech [Fuzhou, People's Republic of China], and used at dilution 1:100).

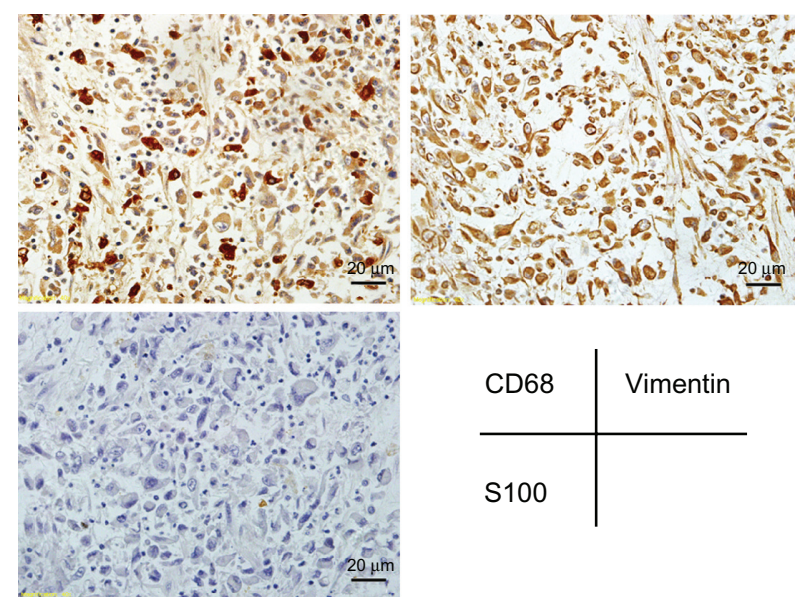

Figure 2 Immunostaining for cluster of differentiation 68, S-100, and vimentin. Note: Scale bar $20 \mu \mathrm{m}$.
A bone ECT scan and plain thoraco-abdominal CT scan during a 9-month postoperative follow-up period showed a metastatic focus adjacent to the abdominal aorta (Figure 1C), whose CT value was similar to that of the primary tumor. The patient was re-admitted for radiotherapy for 3 months. CT scans at 12 and 18 months following the operation showed that the metastatic focus near the abdominal aorta had disappeared (Figure 1D). The patient refused any further treatment, and at the time of writing, 78 months after her first operation, she remains alive.

\section{Discussion}

Renal MFH is a malignant tumor originating from mesenchymal tissue, the pathogenesis of which is unclear. Some researchers believe it is related to scar repair, radiation, chemicals, and/or viral infection. ${ }^{16}$ There have been few cases reported in the literature since Anderson et al reported the first case in 1977. Clinically, MFH of the renal pelvis is similar to carcinoma of the renal pelvis, the diagnosis of which mainly depends on postoperative histology. As the histological presentation of MFH is complex in composition and variable in morphology, it is difficult to use routine pathology to confirm the diagnosis. Immunohistochemistry and/or electron microscopy are needed to confirm the diagnosis. CD68 has become a routine and specific cytohistological marker of $\mathrm{MFH}^{5}$ to replace the former marker alpha- 1 antichymotrypsin, which is stained positive for malignant histiocytes by immunohistochemistry under microscopy. Nemes and Thomazy ${ }^{17}$ emphasized that being positive for Factor VIIIa represents the differentiation level of fibrous histiocytes, and that in soft-tissue tumors with similar pathological morphological profiles, testing positive for Factor VIIIa is the cue for the diagnosis of MFH. Direct invasion is the main characteristic of MFH growth and dissemination, followed by blood and lymph node metastasis, which is usually found at the time of diagnosis. ${ }^{16} \mathrm{MFH}$ is highly malignant, with a high rate of local recurrence and distal metastasis. Fukunaga ${ }^{18}$ reported that MFH originating from the renal pelvis is highly malignant, and most patients die within 12 months of surgical intervention. It is generally accepted that early diagnosis, surgical resection, and accessory radiotherapy/chemotherapy are the main treatment strategies. Early detection is closely related to the therapeutic outcome and prognosis. Regular lifetime postoperative follow-up and positive treatment of recurrence may provide increased chance of longer-term survival.

\section{Disclosure}

The authors declare no conflicts of interest in this work. 


\section{References}

1. Cong Z, Gong J. Primary malignant fibrous histiocytoma of the liver: CT findings in five histopathological proven patients. Abdom Imaging. 2011;36(5):552-556.

2. Sugitani M, Aramaki O, Kikuchi K, et al. Two cases of primary malignant fibrous histiocytoma of the liver: immunohistochemical expression of ezrin and its relationship with prognosis. Acta Histochem Cytochem. 2009;42(3):83-88.

3. Chen Q, Li Q. [Primary malignant fibrous histiocytoma of the liver: an analysis of 3 cases.] Zhonghua Gan Zang Bing Za Zhi. 2006;14(4): 313, 317. Chinese.

4. Colovic N, Cemerikic-Martinovic V, Colovic R, Zogovic S. Primary malignant fibrous histiocytoma of the spleen and liver. Med Oncol. 2001; 18(4):293-297.

5. Schweyer S, Meyer-Venter R, Lorf T, Sattler B, Fayyazi A. [Malignant fibrous histiocytoma of the liver.] Z Gastroenterol. 2000;38(3):243-248. German.

6. Tamaki H, Sanda T, Kawamura K, Ohhashi N, Muneyuki T, Yuasa H. [Malignant fibrous histiocytoma of the liver.] Ryoikibetsu Shokogun Shirizu. 1995;(7):295-298. Japanese.

7. Lieu PK, Ho J, Ng HS. Primary malignant fibrous histiocytoma of the spleen and liver - a case report. Ann Acad Med Singapore. 1993; 22(3):390-392.

8. Reed JG, Goodman P, Soloway RD. Primary malignant fibrous histiocytoma of the liver MRI findings. Magn Res Imaging. 1993;11(1): 139-143.

9. McGrady BJ, Mirakhur MM. Recurrent malignant fibrous histiocytoma of the liver. Histopathology. 1992;21(3):290-292.
10. Akifuji Y, Honjo I, Katayama S, et al. Malignant fibrous histiocytoma of the liver: a case report and review of the literature. Internal Med. 1992;31(2):284-288.

11. Papadopoulos I, Rudolph P. Primary renal malignant fibrous histiocytoma: case report. Urol Int. 1999;63(2):136-138.

12. Singh SK, Mandal AK, Agarwal MM, Das A. Primary renal inflammatory malignant fibrous histiocytoma: a diagnostic challenge. Int J Urol. 2006;13(7):1000-1002.

13. Ptochos A, Karydas G, Iosifidis N, Tyrothoulakis E, Papazafiriou G, Kehagia-Koutoufari T. Primary renal malignant fibrous histiocytoma. A case report and review of the literature. Urol Int. 1999;63(4): 261-264.

14. Ojeda LM, Johnson DE, Ames FC, Raymond AK, Ayala AG. Primary renal malignant fibrous histiocytoma. Urology. 1984;24(5):491-494.

15. Scriven RR, Thrasher TV, Smith DC, Stewart SC. Primary renal malignant fibrous histiocytoma: a case report and literature review. J Urol. 1984;131(5):948-949.

16. Staiman VR, O'Toole KM, Rubin MA, Lowe FC. Giant malignant fibrous histiocytoma of the testis/spermatic cord: psychologic and possible etiologic complications of unethical Nazi medical experimentation. Urology. 1996;48(6):939-943.

17. Nemes Z, Thomazy V. Factor XIIIa and the classic histiocytic markers in malignant fibrous histiocytoma: a comparative immunohistochemical study. Hum Pathol. 1988;19(7):822-829.

18. Fukunaga M. Sarcomatoid collecting duct carcinoma. Arch Pathol Lab Med. 1999;123(4):338-341.
OncoTargets and Therapy

\section{Publish your work in this journal}

OncoTargets and Therapy is an international, peer-reviewed, open access journal focusing on the pathological basis of all cancers, potential targets for therapy and treatment protocols employed to improve the management of cancer patients. The journal also focuses on the impact of management programs and new therapeutic agents and protocols on

\section{Dovepress}

patient perspectives such as quality of life, adherence and satisfaction. The manuscript management system is completely online and includes a very quick and fair peer-review system, which is all easy to use. Visit http://www.dovepress.com/testimonials.php to read real quotes from published authors. 